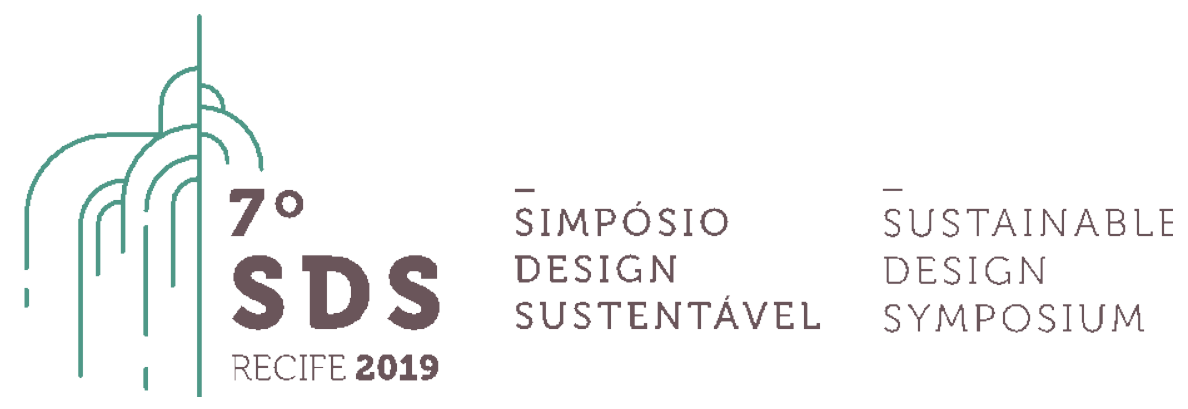

\title{
Sementes Urbanas: aprendizados em um Laboratório de Design para inovação social
}

\author{
Diego dos Santos Costa ${ }^{1}$, Pedro Biz ${ }^{2}$, Julio Cezar Augusto da Silva ${ }^{3}$, Ana Santos ${ }^{4}$, \\ 1 INT, DIDIM, dscosta.c@gmail.com \\ ${ }^{2}$ ESDI/UERJ, PPDESDI, pedrotrg@gmail.com \\ ${ }^{3}$ INT, DIDIM, julio.silva@int.gov.br \\ ${ }^{4}$ CEM, cem.contatos@gmail.com
}

\begin{abstract}
Resumo. $O$ artigo apresenta o Workshop Sementes Urbanas, projeto organizado em parceria entre a ONG CEM, o Instituto Nacional de Tecnologia (INT) e o Laboratório de Design para Agricultura Urbana e Sustentabilidade da ESDI/ UERJ (Espaços Verdes). O Workshop teve como objetivo fomentar a socialização, a segurança alimentar e a geração de renda no Complexo de Favelas da Penha, no Rio de Janeiro. As atividades do workshop tiveram a participação de profissionais e estudantes de design, moradores da Penha e foram baseadas na proposta de laboratório de design e inovação social para sustentabilidade. A experiência é apresentada de forma crítica e busca fomentar a discussão do tema a partir da revisão bibliográfica, o método empregado, o desenvolvimento realizado na primeira fase do WSU e os resultados obtidos. Observamos que o processo de desenvolvimento do workshop - o laboratório de design, foi importante em termos de aprendizado para os designers e não designers, funcionando como ferramenta de aproximação e proporcionando uma maior participação do grupo.
\end{abstract}

Palavras-chave. design para inovação social. sustentabilidade. laboratórios de design. agricultura urbana

\section{Introdução}

Ao longo de sua atuação no Complexo da Penha, a ONG Centro de Integração na Serra da Misericórdia (CEM) realizou diversas atividades de promoção da agricultura urbana. Entre idas e vindas a escolas, creches e a clínicas da família, com objetivo de realizar oficinas - e sempre carregados de mudas e plantas que eram usadas como material pedagógico - foi observado que uma bandeja de mudas é capaz de despertar o interesse do mais tímido dos moradores. Andar pela rua com uma bandeja de mudas é certeza de chegar atrasado ao seu destino. Não há quem não pare e tente adivinhar qual espécie está plantada na bandeja, pedindo uma muda, perguntando se é fácil plantar, contando alguma história antiga da época em que morava na roça $7^{\circ}$ 
ou para perguntar: "tia, o que é isso?". Andar com uma bandeja de mudas é uma ótima maneira de puxar uma conversa. Foi a partir dessas observações que surgiu a ideia de promover o plantio de mudas nos quintais, terraços e instituições da favela. Não é fácil achar mudas não ornamentais na cidade. $E$, se achar, não é barato. Dito isto nos perguntamos: por que não produzir nos quintais e nos espaços ociosos?

Como desdobramento da pergunta acima, o CEM, em parceria com o Instituto Nacional de Tecnologia (INT) e o Laboratório de Design para Agricultura Urbana e Sustentabilidade da ESDI/ UERJ (Espaços Verdes) realizou um workshop de nome Workshop Sementes Urbanas (WSU). O objetivo foi estimular a socialização, a segurança alimentar e a geração de renda no Complexo de Favelas da Penha, na cidade do Rio de Janeiro. O projeto, realizado em 2017, teve sete encontros entre profissionais e estudantes de design, moradores da Penha, e mais duas apresentações de resultados. As atividades do workshop foram baseadas nos conceitos de Laboratório de Design (HALSE et al., 2010) e inovação social para sustentabilidade (Manzini, 2008; 2018) em uma abordagem participativa e sensível ao território para o qual se projeta, promovendo a troca de conhecimento e a colaboração de todos com a finalidade de desenvolver um projeto que fizesse sentido à comunidade.

Neste artigo apresentamos o workshop, a revisão bibliográfica que embasou o trabalho desenvolvido, o método empregado, o desenvolvimento realizado na primeira fase do WSU, os resultados obtidos, as conclusões e as propostas para as próximas fases do projeto. A experiência é demonstrada de forma crítica e busca fomentar a discussão do tema, apresentando sugestões para replicação do projeto e o aprofundamento do saber neste segmento.

\section{Novos discursos e práticas de Design para Sustentabilidade: a inovação social e o design para transição}

Partindo de um conceito ampliado, podemos entender o Design para Sustentabilidade como o campo da disciplina do design que busca atender as necessidades do desenvolvimento sustentável por meio da prática, ensino e pesquisa (Vezzoli et al, 2018). Esse campo de atuação passou ao longo de sua existência por uma evolução na abordagem e, se inicialmente focou-se em aspectos da sustentabilidade mais ligados a natureza dos produtos - Ecodesign, Biomimética, Cradle to Cradle, etc -, hoje lida com questões como o papel e participação dos usuários, comunidades e atores que compõem os sistemas sociais complexos - Sistema Produto Serviço, Design para Inovação Social, Design para Transição, etc. (Ceschin e Gaziulusoy, 2016). Enquanto as primeiras abordagens empregadas no Design para Sustentabilidade têm suas práticas mais estabelecidas, outras ainda não estão plenamente consolidadas. É o caso do Design para Inovação Social e, mais recentemente, do Design para Transição. Ambas as abordagens estão em desenvolvimento e apresentam elevado interesse de pesquisa (Ceschin e Gaziulusoy, 2016). Destacamos esforços da Inovação Social (MANZINI, 2008, 2018), do Design para Transição (Escobar, 2016; Irwin, 2018; Manzini, 2018) e as aproximações entre o Design e a Antropologia (HALSE et al., 2010; GUNN, OTTO, SMITH, 2013) como referências que nortearam o projeto.

A Inovação Social é definida por Ezio Manzini "como novas ideias (produtos, serviços e modelos) que atendem a necessidades sociais e, ao mesmo tempo, criam novas relações ou colaborações sociais" (2018, p. 25)". Uma das diferenças para a inovação "convencional" é a atuação na resolução de problemas vistos como intratáveis pelos caminhos já existentes, tais como desigualdade e epidemias, pois ela indica caminhos viáveis para buscar "soluções que rompam com modelos econômicos formando novos modelos que operam com base em motivações e expectativas de uma multiplicidade de atores" (MANZINI, 2018 p. 27). Inovação social é distinta da inovação "convencional" tanto em termos de resultados quanto em formas de 
relacionamento, pois traz novas formas de cooperação e colaboração entre os envolvidos. Esta inovação pode ser um produto, processo de produção ou tecnologia (bem como a inovação em geral), mas também pode ser um princípio, uma idéia, uma legislação, um movimento social, uma intervenção ou alguma combinação entre eles. (Phills, Deiglmeier e Miller, 2008)

O Design para a inovação social deve ser interpretado como uma atividade de design que tem a finalidade de encorajar a inovação radical orientada para sustentabilidade (Manzini, 2008, p.36). Estas atividades incluem qualquer projeto que o designer "possa iniciar, impulsionar, apoiar, fortalecer ou replicar a inovação social" (Manzini, 2013). Para buscar soluções sustentáveis, Manzini (2008) estabelece como pré-condição mudar a perspectiva de projetar uma coisa para alcançar resultados, ou seja, o projeto não é focado em construir um artefato ou sistema específico, mas alcançar algum fim a partir daquilo que foi projetado. Para entender a questão que está sendo colocada é preciso imaginar alternativas que experimentem diferentes combinações de produtos, serviços, conhecimentos, habilidades organizativas e papéis desempenhados por atores, ampliando a rede de demandas que envolvem uma possível solução.

O autor, entretanto, salienta que projetar para um resultado não é garantia de um projeto sustentável. Este depende que exista consistência com os princípios fundamentais da ética, além de baixa intensidade de energia material e alto poder regenerativo. Entre os princípios apresentados por Manzini (2008, p. 32-34), destacamos: proteger e desenvolver a diversidade biológica, sociocultural e tecnológica; usar o que já existe; proteger o ambiente natural e promover a "natureza simbiótica"; renaturalizar a comida; fortalecer pessoas incrementando a participação; desenvolver redes; promover formas de organização descentralizadas e flexíveis.

Os discursos para transição têm adquirido força nos últimos anos (Escobar, 2016; Irwin, 2018; Manzini, 2018). Defende-se a importância de ir além dos limites institucionais e epistêmicos existentes para lograr transformações significativas. Esses discursos partem da noção de que as crises ecológicas e sociais contemporâneas são inseparáveis do modelo social dominante dos últimos séculos. Neste sentido, o desenvolvimentismo se apresenta como um dos principais discursos e aparatos institucionais que estruturam a insustentabilidade e a eliminação de futuros: a desfuturização (Escobar, 2016). Segundo teóricos da transição, como Arturo Escobar e Ezio Manzini, nossa missão é reinventar o ser humano integrando-o com todos os sistemas vivos. Esse lugar almejado não é algo que se pode chegar, mas que precisa ser criado. É, portanto, a capacidade de imaginar e criar novos mundos que aproxima teorias e práticas de design dos discursos de transição.

Como o design está muito vinculado ao modelo desenvolvimentista, para se imaginar outros mundos a partir do design é preciso primeiro imaginar outras formas de fazer design. Segundo Irwin (2018), as abordagens habituais de Design para Sustentabilidade tendem a enquadrar os problemas em contextos espaço-temporais estreitos e não oferecem uma forma efetiva para identificar todos os stakeholders e seus conflitos, que podem levar décadas para serem resolvidos. A abordagem do Design para Transição, por outro lado, "baseia-se em abordagens das ciências sociais para entender as raízes sociais de wicked problems e colocar as preocupações das partes interessadas e do codesign no coração dos processos de resolução de problemas $^{a "}$ (Irwin, 2018).

A partir das teorias de transição, podemos dizer que as transformações que desejamos construir no Workshop Sementes Urbanas não partem apenas da ação, mas dos discursos que orientam essa ação, assim como da própria abordagem de design que condiciona os mundos que

a Tradução livre dos autores. Optamos por não traduzir wicked problems para manter a noção original da categoria. 
queremos imaginar. As aproximações entre o campo do Design e da Antropologia não se tratam apenas de empregar superficialmente metodologias da antropologia no projeto, como a etnografia, para fazer pesquisa com usuários. O que se discute é uma mudança de olhar para um designer atento e capaz de se colocar no lugar do outro. Para os designers, a antropologia pode contribuir a partir de uma observação e descrição do que é "estrangeiro e exótico em termos que nos permitem nos reconhecer a nós mesmos nos outros, apenas em circunstâncias diferentes" (HALSE et al., 2010, p. 16). A aproximação das disciplinas indica uma mudança "em direção que pode combinar a preocupação de interpretar o mundo criticamente com a intenção de mudar o mundo para melhor" (ANUSAS, 2016). Enquanto a antropologia está mais preocupada em descrever o passado, o design projeta-se ao futuro e a interseção dos dois é uma busca em um tempo presente.

Como referência para o Workshop Sementes Urbanas, utilizamos o conceito de Laboratório de Design proposto por Halse et al. (2010), buscando uma forma de atuar no campo que corresponde ao que se discute sob o nome de Design e Antropologia. Segundo Thomas Binder, os laboratórios se estruturam em uma série de workshops, que, quando unidos com os trabalhos dos participantes durante e entre os workshops, tornam-se "um espaço compartilhado de exploração no qual todos os participantes podem se comprometer" (HALSE et al., 2010, p. 19). É na continuidade dos workshops que torna-se possível aprender, a partir do acúmulo de conhecimento gerado pelos participantes e dos resultados desenvolvidos e observados. $\mathrm{O}$ trabalho vai além do laboratório, pois todos estão envolvidos e trazem suas contribuições gradualmente. 0 "laboratório de design não é isolado das situações do dia-a-dia. Entre eventos, os participantes retornam aos contextos de suas vidas profissionais e privadas e tem a oportunidade de repensar o que foi encenado na colaboração" (HALSE et al., 2010, p. 20). Portanto, consideramos importante projetar a partir da noção de laboratório "para garantir as condições nas quais o que é gerado possa crescer sem ser contestado de forma dura pelo frequente ambiente adverso das realidades do dia a dia" (HALSE et al., 2010, p. 19)

Uma das diferenças dos laboratórios para outras práticas de design é sua orientação ao processo, tomando uma certa abertura sobre as ferramentas e métodos. Em cada Laboratório de Design, essas ferramentas e métodos têm que ser moldadas e afiadas pelas questões e considerações dos participantes. Assim, se promovermos um Laboratório de Design com um conjunto de ferramentas padrão, iríamos (no melhor dos casos) alcançar resultados padronizados já predispostos nessas ferramentas empregadas. Cada experiência deve criar seu próprio repertório de ferramentas e métodos (HALSE et al., 2010, p. 21).

Em consequência, os experimentos produzidos nos workshops não são conclusivos, mas constantemente desenvolvidos. Esse entendimento que o projeto não é conclusivo, ou seja, não tem um fim ou não se encerra ao final do laboratório, é importante em ações que não visam entregar soluções prontas à comunidade. O que se pretende é desenvolver junto, gradualmente, para garantir que o engajamento e a assimilação sejam consistentes.

\section{Workshop Sementes Urbanas}

\section{A formação do workshop}

A formação do workshop Sementes Urbanas iniciou com a atuação do CEM no Complexo da Penha. A ONG trabalha promovendo a agricultura urbana no território e está em constante interação com escolas, creches, centros de assistência social, clínicas etc. Nestes espaços, a instituição promove oficinas e atividades para fomentar o plantio urbano e os benefícios que a 
atividade proporciona (COSTA, 2016). Ao longo dos anos, a ONG percebeu que um dos gargalos para o plantio nas cidades era o acesso a mudas de qualidade, pois eram constantes os pedidos por mudas tanto por parte dos moradores quando das instituições parceiras.

Esta constatação trouxe a reboque uma outra constatação ainda mais importante: as mudas têm grande valor nas cidades, e não apenas um valor econômico. Além de difíceis de serem encontradas, o que naturalmente as tornam mais caras, as mudas possuem uma capacidade quase "mágica" de atrair olhares, iniciar conversas e despertar sentimentos e lembranças. Esta foi uma observação que se mostrou cada vez mais evidente no decorrer de sua atuação no território.

É neste contexto que surge a ideia dos viveiros: por que não produzir nos quintais dos moradores e nos espaços ociosos das instituições do bairro? Além de incentivar a agricultura urbana, a produção poderia gerar renda e promover a socialização dos novos agricultores urbanos. O workshop, por sua vez, foi concebido quando um parceiro da ONG, o Laboratório de Design para Agricultura Urbana e Sustentabilidade da ESDI/ UERJ (Espaços Verdes), apresentou a ideia de desenvolvimento dos viveiros aos pesquisadores do Instituto Nacional de Tecnologia (INT), que se interessaram pela ideia e sugeriram os encontros com o intuito de desenvolver os viveiros de forma compartilhada com estudantes da ESDI e moradores do Complexo da Penha. Desta forma, as três instituições, CEM, INT e ESDI, organizaram o workshop.

Uma das premissas assumidas foi que todas as iniciativas seriam desenvolvidas em conjunto, integrando os atores no planejamento, na concepção dos equipamentos para o plantio, sua construção, divulgação, multiplicação e ações para futura replicação do projeto. Ficou acordado que todo o processo de desenvolvimento e conhecimento gerado fosse de livre acesso para qualquer um que se interessasse. Tais premissas foram viabilizadas com a utilização de uma ferramenta online de organização e gestão projetos, o Trello. Esta é uma ferramenta que permite o compartilhamento de ideias esboços, imagens, textos, livros, links. Os membros também podem lançar comentários no material disponibilizado e adicionar seus próprios materiais. Ademais, os não membros da equipe possuem acesso a todo material ${ }^{\text {b }}$.

O workshop ocorreu durante nove semanas, com um encontro semanal de aproximadamente três horas. Todos os encontros eram combinados por email e confirmados com uma ligação para cada um dos participantes. A reunião era dividida em duas etapas. Inicialmente $o$ grupo recebia as informações necessárias para as atividades daquele dia e, a seguir, iniciava as atividades, que poderiam ser concluídas remotamente e apresentadas na semana seguinte. Ao final, um email era enviado aos participantes com um relato das atividades e os links para acesso do material gerado no dia, o que incluía fotos, esboços, comentários etc. De mesmo modo, todos eram estimulados a adicionar o que fosse desenvolvido ao longo da semana e realizar comentários caso achassem pertinente.

\section{As semanas de workshop}

A primeira semana do workshop foi dedicada à apresentação das instituições - CEM, INT e ESDI, dos participantes e do projeto. O CEM mostrou seu histórico de atuação no território, bem como os insights que levaram aos viveiros e seus objetivos. A instituição também apresentou dados para caracterizar as oportunidades, limitações e restrições da comunidade. De posse destas informações, o grupo realizou o alinhamento das expectativas e pôde detalhar o briefing coletivamente. A atividade a ser realizada de forma remota, ao longo da semana, foi o levantamento de equipamentos semelhantes, materiais e processos produtivos aplicáveis para a

\footnotetext{
${ }^{b}$ Todo material referente ao workshop está disponível no link: http://bit.ly/20crono
} 
situação. Como resultado do primeiro dia, o grupo elaborou uma lista de materiais aplicáveis ao projeto e abundantes na região, a partir da orientação do CEM. Uma série de soluções e técnicas de irrigação caseiras também foram catalogadas, além de uma coletânea de material bibliográfico relacionado ao tema cultivo urbano: livros, manuais, cartilhas, imagens, sítios na internet, tutoriais.

A segunda semana de atividade, foi marcado pela participação e consultoria de um especialista em agricultura urbana. Neste dia cada participante expôs o resultado de sua pesquisa. O grupo discutiu sobre as informações apresentadas e chegou a um consenso sobre materiais e processos aplicáveis. A presença do especialista foi importante na análise do material compilado, pois muito do que é disponibilizado na internet não se aplica a realidade e às vezes não é factível. O grupo também realizou uma problematização, chegando então aos parâmetros projetuais. Em seguida, na parte prática do dia, foi iniciada a conceituação. Essa atividade teve continuidade ao longo da semana como uma tarefa remota. Cada participante desenvolveu suas ideias em esboços manuais, fotografou e inseriu no Trello. Ao todo, foram criadas e registradas 23 ideias.

O terceiro encontro foi dedicado ao estudo do movimento maker e a cultura do faça você mesmo ( $D / Y$, na sigla em inglês), explicada por uma especialista no tema. Na segunda etapa do dia, o grupo deu sequência ao processo de conceituação das ideias, empregando técnicas de brainstorming. Nesta oportunidade novas ideias foram geradas de forma coletiva, agora tendo como ênfase técnicas de $D I Y$. As alternativas puderam ser avaliadas coletivamente e seis foram selecionadas pelo grupo para serem desenvolvidas. Neste momento, houve um cuidado especial para que os designers evitassem interferir no processo de escolha, visto que um olhar técnico poderia inibir a participação do grupo. Nesse sentido, deixou-se claro que o objetivo da avaliação e escolha das alternativas deveria atender aos critérios puramente conceituais e não técnicos, como a viabilidade construtiva ou de funcionamento da alternativa.

Na quarta semana, o grupo fez uma visita ao Complexo da Penha guiada pelos moradores. Neste dia a equipe conheceu lugares para onde os viveiros estavam sendo pensados. Foram visitados o Parque Ary Barroso, a Arena Cultural Dicró, a creche Maria de Lourdes, a Clínica da Família e a Escola Municipal Bernardo de Vasconcelos. Por fim, o grupo visitou a sede do CEM, onde foi servido um almoço agroecológico e realizada uma troca de impressões sobre a situação em campo e como isso influenciava o desenvolvimento do projeto. Diante da diversidade de cenários nos locais de implementação, foi confirmada a necessidades de desenvolver não um, mas um conjunto de viveiros com diferentes características.

A quinta semana foi dedicada à construção de pequenos mockups e modelos (Figura 01) que permitissem uma tangibilização das alternativas escolhidas no terceiro encontro. $O$ material disponível para esse desenvolvimento era propositadamente o mais simples possível e de fácil utilização para que todos pudessem contribuir livremente e sem dificuldades. As seis alternativas foram modeladas e apresentadas pelos participantes. Também neste dia, uma outra equipe se dedicava a elaboração de um esquema visual que organizasse graficamente as interrelações entre os viveiros, os atores envolvidos e o modelo de funcionamento do fluxo de mudas no território.

Figura 1 - Modelos dos viveiros publicados na plataforma trello 


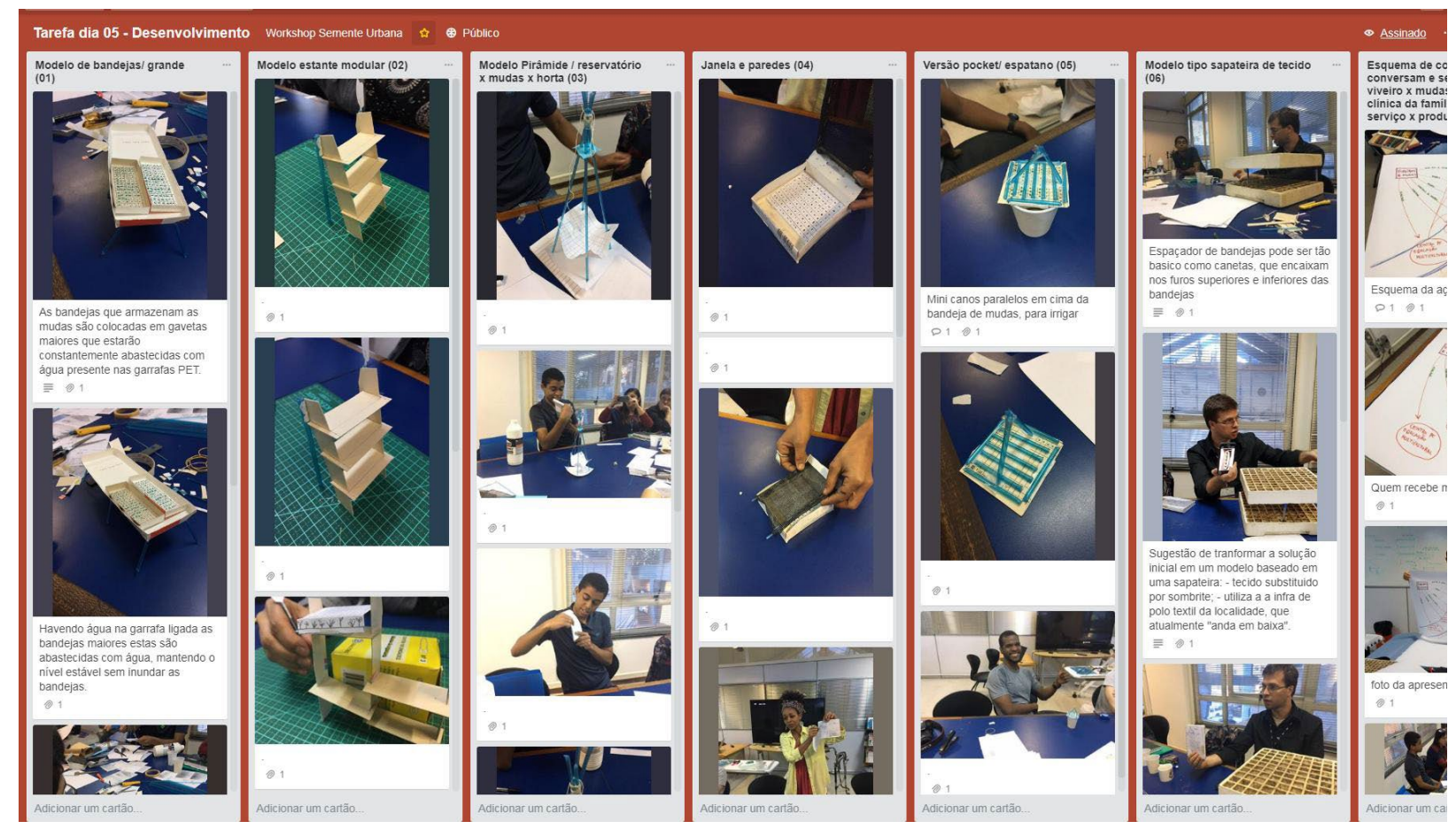

Fonte: Elaborado pelos autores

O sexto encontro foi dedicado a uma avaliação mais aprofundada das alternativas desenvolvidas. O grupo revisou cada um dos modelos pensando nos aspectos construtivos e de funcionamento e levou em conta principalmente a utilização de materiais e ferramentas disponíveis no território. Com a colaboração de todos foram preparadas listas de materiais possíveis e ferramentas disponíveis para construção das seis alternativas de viveiros. Mais uma vez, houve a preocupação de não descartar nenhum comentário ou sugestão, para que todos tivessem suas contribuições registradas e possíveis de serem testadas posteriormente. Em paralelo, o esquema do fluxo de mudas entre os atores do território também foi trabalhado pelo grupo que se dedicou a esta atividade.

No sétimo encontro foram discutidas as apresentações dos resultados do workshop. Neste dia, tendo as alternativas consolidadas (conceito, material e funcionamento), os designers assumiram o papel de geradores das ilustrações e desenhos esquemáticos de cada um dos viveiros, e se responsabilizaram pela preparação das apresentações. Também foram discutidos desdobramentos e oportunidades do projeto. Na conclusão deste dia foi realizado uma dinâmica de grupo, onde cada participante apresentou suas percepções de todo o processo.

As duas últimas semanas foram dedicadas às apresentações realizadas no INT e na ESDI. As demonstrações contaram com a presença de membros da comunidade, de multiplicadores do Complexo da Penha e de outras comunidades, pesquisadores do INT, estudantes, professores e profissionais convidados relacionados aos temas - como agronomia e certificação de orgânicos.

\section{Os viveiros}

Das 23 ideias iniciais, seis alternativas foram escolhidas e desenvolvidas pelo grupo. Os viveiros foram pensados para funcionar em diferentes contextos, de acordo com o seu tamanho e característica, servindo a diferentes parceiros na comunidade. Também houve a preocupação em utilizar materiais disponíveis e abundantes, como garrafas PET e tubos de PVC, além de serviços prestados por pessoas do território como de soldadores e costureiras. Essas medidas trazem mais garantias que é possível construir e replicar viveiros sem o acompanhamento dos designers em ocasiões futuras. 
Todos os viveiros estão representados na figura 2. O modelo 1 é um viveiro de grande porte capaz de produzir até 400 mudas por mês. Ele pode ser utilizado em espaços como a creche, escola ou clínica da família, lugares com mais espaços livres. O modelo 2 é uma estante modular de médio porte que funciona como mostruário e estrutura de produção. 0 modelo 3 foi pensado para espaços coletivos mas com pouca área disponível; ele possui um reservatório de água maior que diminui a necessidade de manutenção. $O$ modelo 4 é um viveiro de janela, voltado para as casas que não possuem quintal. 0 modelo 5 é um viveiro para pequenos espaços e possui rodinhas para acompanhar a movimentação do sol ao longo do ano. E, por fim, o modelo 6 foi pensado como mostruário e para o transporte de mudas em ônibus e trem, o que é importante quando consideramos a comercialização

Figura 2 - Ilustração dos seis modelos desenvolvidos.

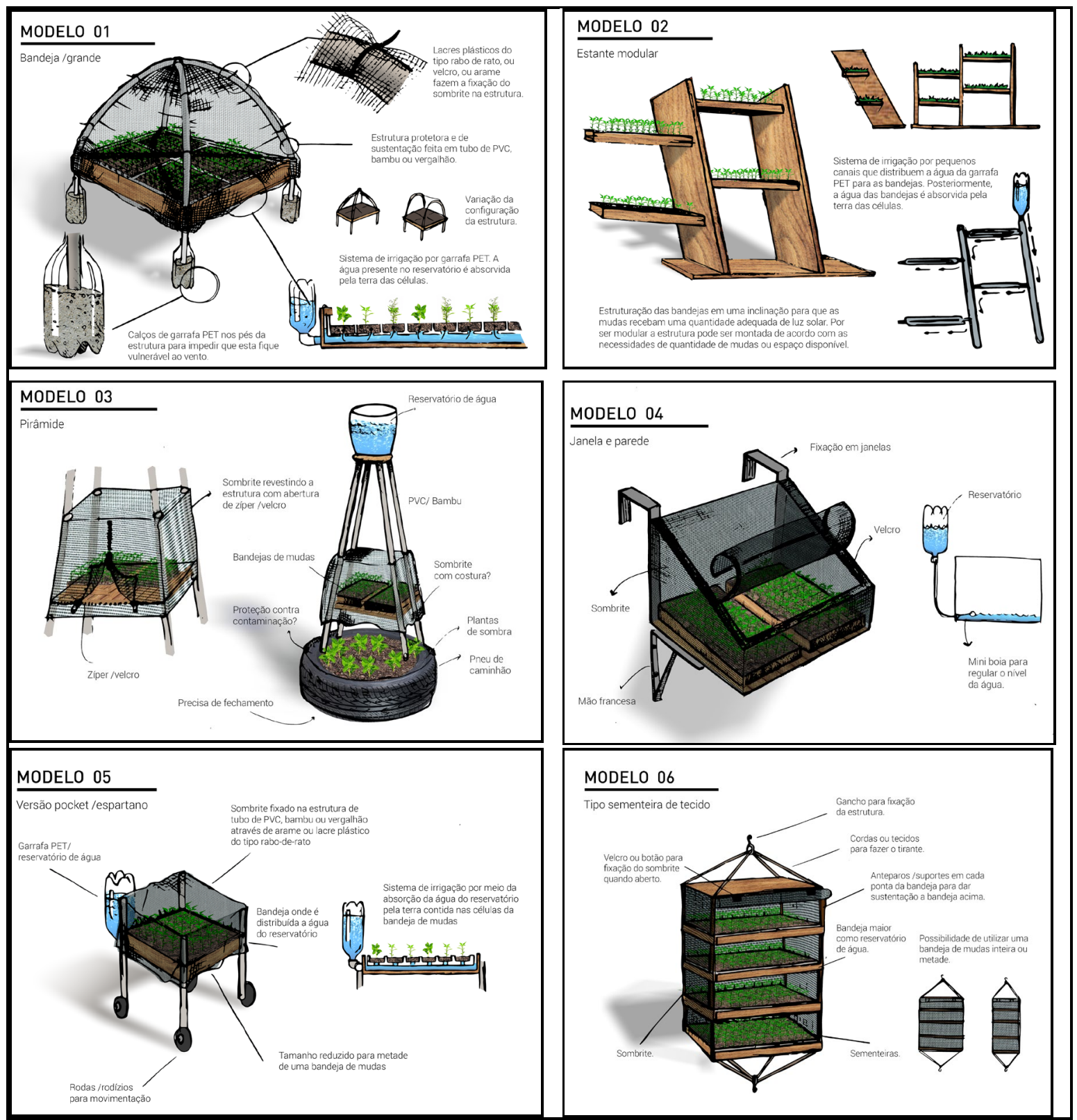

Fonte: Elaborado pelos autores

No projeto da organização do sistema todas as mudas seriam cultivadas de maneira descentralizada nos quintais dos moradores e em instituições locais, servindo tanto para 
comercialização em feiras da região, quanto para troca entre os produtores e para cultivo na própria comunidade. Desde forma, além dos benefícios econômicos, os viveiros também promoveriam um intercâmbio de saberes e práticas entre os produtores (socialização) e dariam acesso a mudas de qualidade para que os moradores possam cultivar suas próprias hortas - o que resultaria no aumento da área verde no território e melhoria no consumo de alimentos com qualidade.

\section{Discussão}

Baseamos o desenvolvimento do Workshop Sementes Urbanas nos conceitos de Laboratório de Design propostos por Halse et al. (2010), no qual as atividades se estruturam em uma série de workshops. No WSU as atividades ocorreram ao longo de nove semanas com a realização de encontros semanais. Percebemos que, ao projetarmos como um Laboratório de Design, ou seja, num espaço de tempo maior separado em workshops, obtivemos uma contribuição mais efetiva de todos os participantes, pois todos tiveram oportunidade de repensar ao longo da semana as ideias desenvolvidas em cada encontro (Halse et al. 2010). Do mesmo modo, observamos que conforme o workshop se desenvolvia a convivência tornava as interações mais efetivas, melhorando as contribuições de cada um dos participantes. Na medida em que cada participante ficava à vontade para interagir e contribuir, novas questões e pontos de vistas surgiam e enriqueciam o processo, fazendo com que todos tivessem que repensar seus pontos de vista quanto ao que se projetava. Conforme percebíamos mudanças nas respostas dos participantes, tivemos a possibilidade de rever as atividades dos workshops adaptando ao nível de desenvolvimento do grupo em relação ao projeto.

Nesse sentido, encontramos no Laboratório de Design uma ferramenta de Design para Transição, pois quando projetamos em um espaço maior de tempo, permitimos que todos exponham seus interesses, evidenciando conflitos e possibilitando que cada interessado apresente suas preocupações. Essa abordagem vai de encontro com o Design para Transição quando busca "entender as raízes sociais de wicked problems" e coloca "as preocupações das partes interessadas e do codesign no coração dos processos de resolução de problemas" (Irwin, 2018).

O WSU não envolveu apenas o desenvolvimento de viveiros. Conforme apontou Manzini, projetos guiados à sustentabilidade enfocam em um fim e não em um artefato como a possível solução. Mais do que projetar objetos, o projeto norteou o cultivo comunitário de mudas e seu fluxo econômico, as redes que articulam o manejo, produção e comercialização das mudas. Durante o workshop, os viveiros funcionaram como algo tangível e de fácil compreensão por todos para se pensar em questões mais complicadas e intangíveis do projeto e suas possíveis combinações para se alcançar uma solução sustentável viável, como bem colocou Manzini (2008). A sustentabilidade deste projeto está baseada na distribuição descentralizada desses viveiros pela comunidade, formando uma cooperativa de cultivo que se ajuda, troca, compartilha aprendizados, enfim, se fortalece em conjunto.

O mundo que buscamos imaginar durante o workshop foi de autonomia para um grupo de moradores da Penha em simbiose com o meio ambiente. Essa autonomia seria guiada por uma "transição social liderada pelo design até um futuro mais sustentável [...] originadas de um pensamento de longo prazo, orientadas ao estilo de vida e baseadas no lugar e sempre reconhecem o mundo natural como o contexto amplo para das as soluções de design" (ESCOBAR, 2016, p. 157). A autonomia que Escobar defende parte de dentro da comunidade e tem 0 designer e suas ferramentas como um facilitador desse processo. Enquanto no processo de design tradicional, o profissional estuda os usuários para desenvolver o projeto, e trabalha como um "tradutor", no processo de co-design o designer assume o papel de facilitador assumindo que 
todos têm capacidade de projetar seu próprio mundo (MANZINI, 2018).

Um dos pontos chave do WSU foi assumir desde o início a importância da participação da comunidade em todas as etapas. Todos pesquisavam, criavam, desenhavam juntos, trazendo para o grupo seus referenciais e experiências de vida e, ao mesmo tempo, aprendendo uns com os outros. Nesse sentido os Laboratórios de Design propiciam um quadro para organização e guia da inovação com ênfase no aprendizado. Em vez de separar pesquisa, ideação e desenvolvimento do conceito do design e da implementação, o Laboratório de Design configura uma organização de aprendizados desde o início (HALSE et al., 2010, p. 21).

Ao reconhecermos que existem diferentes níveis de criatividade, torna-se evidente que precisamos aprender como oferecer experiências relevantes para facilitar a expressão criativa das pessoas em todos os níveis (SANDERS e STAPPERS, 2008, p. 13). Durante todo o workshop os designers buscaram não fazer críticas que indicassem caminhos ao projeto. Evitou-se usar a experiência profissional de designer como filtro. A intenção era permitir ao máximo que os participantes pudessem desenvolver, avaliar e tirar conclusões para tomar as decisões. Todas as ideias foram debatidas e avaliadas, sempre com a preocupação de evitar avaliações que pudessem desmotivar a realização de alguma alternativa. Por fim, os projetos foram escolhidos pelo grupo.

Ainda nessa mudança de posicionamento do designer observamos, a partir dos apontamentos da intersecção do designer e da antropologia, que ir a campo e conhecer o território e seus habitantes a partir de um olhar mais sensível ao contexto em suas conexões, desafios, e linguagem, foi fundamental. Durante o workshop ficou patente que a ida ao Complexo da Penha teve um impacto no andamento do projeto. Optamos por realizar a visita no meio do desenvolvimento do trabalho, ao invés de no primeiro encontro, para antes estabelecer um olhar crítico nos participantes sobre o projeto e o modo de projetar. A partir daí a percepção sobre o lugar não era apenas como morador ou como alguém que não costuma frequentar a favela, mas de designers atentos e empáticos analisando as possibilidades de implementação de um sistema de cultivo de mudas, nos locais visitados, a partir dos desenvolvimentos e aprendizados do WSU.

Foi no trabalho de campo que nos interessou pensar uma posição diferente e mais profunda para o designer. Um projeto que busca desenhar outras possibilidades de vida em uma comunidade demanda uma percepção mais sensível e uma atuação menos impositiva. Um futuro caminhado em conjunto com designers, parceiros, moradores, plantas, animais, coisa, a Terra etc. O campo é o lugar que se está

estudando, conceituando, e experimentando com relações potenciais entre pessoas, práticas e coisas [...], que envolve constantes reflexões e reconceituações. Não é somente prover descrições detalhadas de práticas de usuários como combustível para a imaginação dos designers sobre futuros produtos, mas sim sobre explorar e trabalhar com conceituações e reenquadramentos das relações entre pessoas e coisas, a fim de aumentar o potencial de criação de designers e usuários. (KJ/ERSGAARD e OTTO, 2012, p. 189)

$\mathrm{Na}$ ida ao campo foram percebidas algumas mudanças no comportamento dos integrantes do grupo que indicaram um aumento no comprometimento com as atividades propostas e uma aproximação maior entre eles. Com os aprendizados da visita, consideramos oportuno realizar uma dinâmica de grupo com o objetivo de verificar o significado ou o simbolismo de alguns aspectos vivenciados, possibilitando um espaço para a comunicação, a expressão de percepções e de questões mais sutis do processo coletivo.

A possibilidade de revisar e mudar do roteiro do WSU, conforme sugerida pela abordagem de Laboratório de Design, permitiu analisarmos outros aspectos que interferiram no processo de aprendizagem. Os membros do grupo de trabalho perceberam, a partir da dinâmica, as semelhanças e diferenças das expectativas, dos interesses individuais e comuns ao grupo e da 
diversidade de experiências anteriores. A partir do compartilhamento das ações foi possível agregar todos estes aspectos para alcançar resultados efetivos no processo de criação e uma maior integração destes em prol de um objetivo comum. Ao final, quando perguntados se o processo tinha proporcionado alguma transformação em seu entendimento sobre os temas tratados, os participantes relataram mudanças na percepção da importância de diferentes saberes em todo o processo como o do olhar coletivo, o cuidado com o outro, a empatia, o respeito ao tempo individual e de como as relações estabelecidas podem transformar a percepção de mundo.

\section{Conclusão}

Este artigo apresentou uma experiência da aplicação do conceito de Laboratório de Design no Complexo de Favelas da Penha, na cidade do Rio de Janeiro. Chamamos essa experiência de Workshop Sementes Urbanas, que teve a primeira etapa concluída em novembro de 2017, tendo como resultado o projeto seis modelos de viveiro de mudas e seu sistema de articulação comunitário do cultivo das mudas. $O$ processo e os resultados estão disponíveis e abertos para consulta e replicação na internet. O detalhamento dos modelos de viveiros aprovados está previsto para próxima fase do workshop com o acompanhamento da construção dos protótipos. Nesta etapa, pretendemos aprimorar a metodologia de aplicação do workshop, ampliando a participação de moradores e instituições do território para implantação dos viveiros na comunidade.

Ao realizarmos um workshop aberto, em formato de laboratório, observamos que a participação do grupo aumentou à medida que os encontros aconteciam. Em particular, a participação dos moradores foi mais intensa após a visita ao Complexo da Penha, onde eles guiaram o grupo pelo território. A dinâmica do workshop mudou de acordo com o seu desenvolvimento. A contribuição dos designers passou por uma abordagem menos intervencionista e mais atenta ao que o grupo desenvolvia, o que demandou um cuidado com as ferramentas utilizadas e evitou inibir as ideias que se conectavam com o repertório e as experiências dos participantes.

A partir dessa vivência percebemos o Laboratório de Design como uma ferramenta de Design para Transição e acreditamos que o workshop pode ser ministrado em outras comunidades, buscando as questões importantes para aquela rede, seguindo premissas de projeto iniciais, sem, no entanto, replicar sua dinâmica e ferramentas.

Para fechar com uma boa notícia, o projeto baseado no WSU foi selecionado no programa de Apoio ao Empreendedorismo de Impacto Socioambiental do Estado do Rio de Janeiro 2018, da FAPERJ, para a implementação de viveiros para cultivar mudas de plantas e unidades de compostagem na Penha. Chamada Arranjo Local da Penha, a iniciativa prevê uma atuação de 24 meses sendo 22 dedicados à cocriação e repasse da tecnologia, garantindo que o cultivo de mudas e a compostagem tenham sido assimiladas pelos beneficiários. A proposta é uma parceria da organização não governamental Centro de Integração da Serra da Misericórdia (CEM), do Instituto Nacional de Tecnologia (INT) e da Escola Superior de Desenho Industrial da UERJ (ESDI/UERJ).

O presente trabalho foi realizado com apoio da Coordenação de Aperfeiçoamento de Pessoal de Nível Superior - Brasil (CAPES).

\section{Referências}

ANUSAS, Mike. Different Presents in the making. In: Otto, T. e SMITH, R. (Orgs.). Designing Anthropological Futures. Bloomsbury, 2016. 
COSTA, Diego dos S.. Projetando para agricultura urbana: um estudo de caso no complexo de favelas da Penha, Rio de Janeiro. Dissertação de mestrado. Programa de Pós-graduação em Engenharia de Produção, Universidade Federal do Rio de Janeiro. Rio de Janeiro, 2016.

ESCOBAR, Arturo. Autonomía y diseño. La realización de lo comunal. Popayán: Universidad del Cauca. Sello Editorial, 2016.

CESCHIN, Fabrizio; GAZIULUSOY Idil, Evolution of design for sustainability: From product design to design for system innovations and transitions. Design Studies. Volume 47, P. 118-163. 2016.

HALSE, J.; BRANDT, E.; CLARK, B.; BINDER, T. Rehearsing the future. Copenhagen: The Danish Design School, 2010.

KJ/ERSGAARD, Mette e OTTO, Ton. Anthropological Fieldwork and Designing Potentials. In: GUNN, W.; DONOVAN, J. (Orgs.) Design and Anthropology. Farnham: Ashgate, 2012.

MANZINI, E. Design para inovação social e sustentabilidade. Rio de Janeiro: E-papers, 2008.

MANZINI, E. Making Things Happen: Social Innovation and Design. Design Issues: Volume 30, Number 1. 2013.

MANZINI, E. Design, When Everybody Designs - An Introduction to Design for Social Innovation. The MIT Press. 2015.

Murray, R., Caulier-Grice, J. and Mulgan, G. The open book of social innovation. London: NESTA. 2010.

Phills Jr., James A., DeigImeier, Kriss e Miller, Dale T.. Rediscovering Social Innovation. Stanford: $\begin{array}{llll}\text { Stanford Social Innovation } & \text { Review, }\end{array}$ https://ssir.org/articles/entry/rediscovering_social_innovation

SANDERS, E. B.; STAPPERS, Pieter Jan. Co-creation and the new landscapes of design. Co Design, $v$. 4, n. 1, p. 5-18, 2008.

IRWIN, T. The Emerging Transition Design Approach. In Proceedings of DRS Catalyst. University of Limerick, Ireland. 2018.

VEZZOLI, C.; CESCHIN, F.; OSANJO, L.; M'RITHAA, M.K.; MOALOSI, R.; NAKAZIBWE, V.; DIEHL, J.C. Designing Sustainable Energy for All, Sustainable Product-Service System Design Applied to Distributed Renewable Energy. Springer. 2018. 